ScienceDirect

BIOETHICS UPdate 6 (2020) 37-45
BIOETHICS UPdate

UNIVERSIDAD

PANAMERICANA

www.elsevier.es/bioethicsupdate

Artículo original

\title{
Bioética: imágenes de piezas quirúrgicas en redes sociales. Un comentario a partir de una encuesta informal
}

\author{
Bioethics: photographs of surgical pieces in the social media. \\ Comments from an informal survey \\ J.E. Gómez-Álvarez* , José Enrique Gómez-Álvarez \\ y Nora Hilda Chávez-Hernández \\ División de Bioética, Centro de Investigación Social Avanzada, Santiago de Querétaro, México \\ Recibido el 4 de diciembre de 2019; aceptado el 29 de diciembre de 2019 \\ Disponible en Internet el 1 de marzo de 2020
}

\section{Resumen}

Abordamos en una primera sección la dignidad humana manifestada y ejemplificada a través del cuerpo humano. Se presentan ejemplos de cómo, a través de la legislación, se imponen límites y regulaciones del uso de las partes corporales. El pensar el cuerpo como manifestación de lo digno que hay en el humano, otorga bases conceptuales para no exponerlo innecesariamente. En la segunda sección comentamos los resultados de una encuesta de opinión levantada entre diversos profesionales de la salud en torno a la conveniencia o no de exponer las partes corporales. Discutimos y concluimos que las partes del cuerpo al menos pueden representar

\footnotetext{
* Autor para correspondencia.

Correo electrónico: jegomezalvarez@yahoo.com (J.E. Gómez-Álvarez).
} 
parte de una persona como un todo y, por tanto, deben ser tratadas con respeto y solo mostrarse bajo consentimiento informado y con fines de enseñanza y concientización.

(C) 2020 Publicado por Masson Doyma México S.A. en nombre de Centros Culturales de México, A.C.

Palabras clave: Cuerpo humano; Legislación; Bioética; Fotografías

Abstract: The first section of the article explores human dignity, as well as the human body as a manifestation of that dignity. Examples of how, using legislation, limits and regulations are imposed on the use of body parts. In the second section of the article, using a small survey among different professionals about this topic, an analysis and discussion is presented on the ethical implications of exposing body parts. It is concluded that body parts should only be presented, for educational purposes and social awareness campaigns.

(C) 2020 Published by Masson Doyma México S.A. on behalf of Centros Culturales de México, A.C.

Keywords: Human body; Legislation; Bioethics; Photographs

\section{Introducción}

¿Cuál es el límite de la posesión de mi yo? (Abbagnano 1986; Brahams 1998; Kimberly y Dina 2009). ¿Por qué debemos o deberíamos tener un control sobre las partes del cuerpo? Estas preguntas son cruciales para comprender los límites y consideraciones que deben tenerse ante las piezas quirúrgicas «sobrantes» de diversas intervenciones clínicas. Las partes humanas se constituyen en algo de nosotros como un todo (Kimberly y Dina 2009; Bergel, 2007; Aguado, 2006; Ramírez, 2017). En este artículo argumentamos algunos elementos para regular la exposición visual de esas partes de un cuerpo humano, piezas que constituyeron parte de una persona. La condición de posibilidad del respeto a la persona implica un manejo respetoso de aquello que le constituyó. A partir de la noción de persona, defendemos el rechazo a exponer al público en general las piezas quirúrgicas sobrantes. Para ello, abordamos una primera sección sobre la dignidad humana manifestada a través del cuerpo y se muestra lo que la literatura ha dicho sobre su regulación. En la segunda sección, comentamos una breve encuesta exploratoria entre profesionales de la salud en torno a este tema. Cerramos con las conclusiones. 


\section{El cuerpo como propiedad o como tutela: dignidad humana asociada al cuerpo}

Aun en casos extremos, como las ejecuciones de personas, se han dispuesto limitaciones al manejo del cuerpo de la persona ejecutada. Se suele considerar su cuerpo en tutela, pero no es propiedad de nadie. La Ley General de Salud señala en su artículo 346: «Los cadáveres no pueden ser objeto de propiedad y siempre serán tratados con respeto, dignidad y consideración» (SSA. Ley General de Salud 2018). En el mundo anglosajón, según algunos autores (Brahams 1998), existen vacíos legales respecto al tema, pero la actitud práctica hacia las partes corporales es la misma:

English and Australian law fail to recognise the right to possession of a human corpse or cadaveric specimens and thus there can be no effective remedy for damage or unauthorized removal. There is no duty imposed on hospitals to retain tissue removed at postmortem examinations against the possibility that it might be material evidence in a civil litigation in the future. The question of proprietary or merely possessory rights in the numerous skeletons and anatomical specimens in museums and medical schools has yet to be clarified (Hudson, 1997, p. 91).

Dando por sentado que se mantenga en secreto la identidad del paciente y que no exista afectación en la calidad de la cirugía o de la muestra, ¿es aceptable, en consecuencia, que se difundan las imágenes fotográficas de las piezas quirúrgicas extraídas de un paciente? Da la impresión de que sí, pero esta actitud es básicamente utilitarista, en la que pareciera que el fin justifica los medios. La Ley General de Salud dice (el subrayado es nuestro):

Artículo 350 Bis 3.- Para la utilización de cadáveres o parte de ellos de personas conocidas, con fines de docencia e investigación, se requiere el consentimiento del disponente. Tratándose de cadáveres de personas desconocidas, las instituciones educativas podrán obtenerlos del Ministerio Público o de establecimientos de prestación de servicios de atención médica o de asistencia social. Para tales efectos, las instituciones educativas deberán dar aviso a la autoridad sanitaria competente, en los términos de esta Ley y demás disposiciones aplicables (SS. Ley General de Salud 2018).

Aunque la norma alude solo a los cadáveres, parece claro que aplica el principio de máximo beneficio a la persona (principio pro persona). Si en el caso de cadáveres 
incluso está restringido el uso de sus partes, con mayor razón la que es extraída de una persona viva que puede objetar o dar su consentimiento.

No es lo mismo mostrar fotos o videos en un foro médico para crear conciencia de la relevancia del caso o para instruir sobre la técnica quirúrgica; aun así se requiere consentimiento. En ocasiones, la realidad excede a la regulación.

Pero, ¿qué sucede con, por ejemplo, el caso real de un cirujano conocido de los autores, que ya terminada la cirugía posó con un colon al cuello como si fuese una boa y subió la imagen a una red social? En última instancia puede insistirse en que esas partes ya son solo objetos de desecho. De nuevo, la duda surge en tanto que el cuerpo:

...resulta, a la vez, condición de ser y componente de este sujeto corpóreo, «consistente», unitario y unido al mundo por una «corporeidad» tan prodigiosa como inefable, pues la unidad de este «ser» es a la vez la de su inserción en el mundo. Este sujeto-hombre, efectivo, real, concreto, no se limita a poseer conciencia o cuerpo o a enfrentarse con la realidad externa, es a la vez conciencia y cuerpo, o conciencia-cuerpo, comprometido en el mundo. Este modo del ser postula la unidad de la experiencia y el saber (Crisorio, 2018:13).

Este supuesto sujeto objeto de la corporeidad es lo que sugiere el respeto de sus partes constitutivas. En muchos países, las revistas médicas solicitan un consentimiento informado suscrito por el paciente para difundir imágenes en las cuales se puede identificar el paciente; sin embargo, no siempre se especifica bien cuáles son las imágenes que requieren consentimiento. (Kaan, 2010).

Pese a las minucias legales que implica la publicación de una imagen de piezas quirúrgicas, de fondo, la cuestión que se plantea es el trato al cuerpo. Hay detrás de estas consideraciones una valoración de las partes del cuerpo como medios que, al menos, simbolizan a la persona en su conjunto. El hecho de haber sido partes de personas, nos parece, supone una concepción ontológica sobre el cuerpo que nos impide un uso lúdico o libre de sus partes. La influencia en la concepción cartesiana del cuerpo en donde la persona es el yo mental y el cuerpo solo es poseído, pero no es parte constitutiva del mismo yo, fomentó esa cosificación del cuerpo (Burgos 2017; Beorlegui, 2017).

Aunque de modo analógico una parte del cuerpo hace alusión a su salud, y a pesar de que propiamente no lo sea, es símbolo de esta. Asimismo, nos recuerda en 
su operar concreto y su fragilidad (Oliva-Portolés 2015; Delormé, 2016). Fragilidad que se expone en el arte contemporáneo. De ahí, que en sentido estricto no podemos poseer los cuerpos ni las partes de nadie. Lo que solemos realizar es, más bien, una tutela de este.

Probablemente ese sentido de disposición y posesión proviene de esa reducción a una mercancía, a una banalización:

Es la visión meramente desesperanzada del mundo en que se basa el gran negocio del consumismo moderno y que opera mediante una simple inversión de todo lo que antes se tenía como secundario y que ahora pasa a ocupar el lugar primario. El cuerpo contra el alma, la salud corporal contra la salud integral, el deporte contra la cultura, el sexo contra el erotismo y el amor; en fin, el interés individualista y egocéntrico contra toda idea de trascendencia, valor, sentido... No por nada, el mundo se observa como un largo espacio de sin sentido y sin valor. El individualismo superficial (light) de la sociedad posmoderna va unido a esa visión reduccionista, a esa ideología del cuerpo, a esa reducción de la filosofía del cuerpo a un asunto objetivista y hasta mercadotécnico. Se asume por todos que el cuerpo es el último y único baluarte de la persona. El cuerpo es convertido, compulsiva y neuróticamente, en el único asunto y único objetivo de la «vida» (Ramírez, 2017, p. 58).

El cuerpo, mi cuerpo, no es solo una extensión manipulable por mí o por otros (Mendoza-Valdés, 2013; Burgos, 2017; Beorlegui, 2017). En este sentido es una extensión de mi existencia. Esta idea conlleva el carácter simbólico y significativo de las partes que lo componen (Battan 1999; Oliva-Portolés 2015). De ahí deriva la idea de que a nadie le pertenecen las partes de nadie.

Cabe mencionar que existe una diferencia entre lo que es ético y lo que es legal. Consideramos ético compartir una imagen de un cuerpo o parte de este, siempre y cuando sea bajo consentimiento del paciente, sin que se le identifique y con respeto. Mostrar la imagen tampoco debe afectar la calidad del procedimiento quirúrgico y el propósito debe ser exclusivamente pedagógico o para la concientización, habida cuenta de que no se dispone de otro medio para la enseñanza o aprendizaje del procedimiento o intervención. Esto se justifica porque se mantiene el mínimo de respetar el consentimiento de una persona, además de respetar el principio bioético de solidaridad.

La práctica clínica siempre hace alusión a personas y las personas siempre están corporizadas. No tratamos personas con solo su espíritu, sino en un todo complejo que 
es la extensión y medio de contacto con el mundo (Oliva-Portolés 2015; Delormé, de $\mathrm{B}, 2016)$. Las partes de las personas representan ese medio de manifestar su identidad, de ahí el fundamento para tratarlas con cautela y consideración (Angelcos, 2017). En la misma donación de órganos (Gómez-Alvarez 2003; Altamirano y Robles, 2006) se plantea ese mismo cuidado: el respeto a la identidad del donante por ejemplo, aunque el órgano ya no sea de utilidad para este.

¿Qué piensan los colegas acerca de esto? Veamos ahora la muestra exploratoria.

\section{Encuesta a cirujanos respecto a difusión de imágenes quirúrgicas y de piezas de patología}

Se le realizó un muestreo por conveniencia a 26 cirujanos mexicanos que trabajan en unidades públicas en México: ${ }^{1} 11$ oncocirujanos, 8 cirujanos generales, un oftalmólogo, un otorrinolaringólogo, un urólogo, un ortopedista, un proctólogo, una ginecóloga.

Al cuestionarles si solicitan consentimiento para tomar fotografía o video en cirugías: diez respondieron que no; dos que solamente si se logra identificar al paciente y catorce contestaron que sí.

Se les preguntó si consideran aceptable la difusión de imágenes de cirugía o productos de resección para enseñanza o foros de médicos. De ellos 24 respondieron que sí, y dos que no.

Se les inquirió en cuanto a si consideran aceptable la difusión de imágenes de piezas quirúrgicas en redes sociales considerando que no se pueda identificar al paciente. Once respondieron que sí, tres de los once con notas condicionando a que sea con fines educacionales y con respeto. Quince respondieron que no.

Por lo tanto, el punto más controversial fue el de la difusión de las imágenes en redes sociales, predominando un rechazo a esta práctica entre los cirujanos de esta muestra.

\footnotetext{
${ }^{1}$ La selección se hizo por conocidos de la Dra. Nora Hilda Chávez Hernández a través de vía electrónica, telefónica y en persona como criterio que tuvieran práctica profesional activa en hospitales públicos. Se les pidió consentimiento para el estudio por las mismas vías de comunicación usadas.
} 
Por las respuestas, se percibe una autolimitación de la difusión de las imágenes, restringiéndola al uso médico. No obstante, un grupo alto de ellos no piden consentimiento de la difusión, aun cuando no se pueda identificar al paciente. Comentamos en la sección primera que legalmente se debe solicitar el consentimiento sin importar el riesgo de identificación del paciente por medio de las fotografías. Asimismo se ha comentado que no basta la razón pragmática del cálculo de las meras consecuencias para decidir la moralidad del acto, por ejemplo el médico pudiera ser demandado porque un paciente fue identificado por medio de una fotografía. La razón ontológica es más profunda como hemos visto. El carácter simbólico de la unidad corpórea humana nos obliga a respetar todo lo que alude a esa unión de la persona corporal. Así, los resultados de la encuesta apuntan a que probablemente hay que trabajar más en la defensa de la integridad personal y que implica una disposición de las partes adecuada al estatuto digno de las personas.

\section{Conclusiones}

La literatura clínica y el personal en general concuerdan en que hay límites que no deben trasgredirse. Se descubre, en principio, que concuerda la legislación y la opinión médica de que los cadáveres y sus partes no son objeto de entera disposición. Pese a ello, hay un grupo que parece no manifestar como algo crucial el consentimiento informado del paciente. Esto lleva a la reflexión de que quizá debería hacerse énfasis en las áreas de enseñanza (Ramírez, 2017) en los protocolos del manejo de piezas quirúrgicas.

La Bioética (Tealdi, 2008; Van Dick, 2006) nos da pistas para considerar las piezas quirúrgicas no solo como objetos desechados, sino como partes de una persona. La opinión general es que hay que solicitar autorización en cuanto al uso de imágenes de las partes del paciente. La encuesta demuestra que falta trabajar más en esos temas y no darlos por supuesto. Se precisa conformar criterios éticos aplicables a los protocolos de cada unidad hospitalaria, de modo que el énfasis quede en el respeto personal, es decir, tratar las partes y las imágenes obtenidas de ellas como representación de la humanidad de cada uno de nosotros.

\section{Conflicto de intereses}

Los autores declaran no tener ningún conflicto de intereses. 


\section{Referencias no citadas}

Crisorio, 2016, Escobar:-Triana, 2007, Garcìa G., 2005, Jonson, 2011, Kaan, 2017, Komesaroff y Gardner, 2015, and Vásquez Rocca, 2008.

\section{Referencias}

Abbagnano, N. (1986). Diccionario de Filosofía (1. a edición, pp. 269). México: Fondo de Cultura Económica.

Aguado, J. C. (2006). Cuerpo humano, imagen corporal y ética médica Ética clínica Una perspectiva transfuncional. pp. 211-224. México: Corinter.

Altamirano, N. y Robles, C. (2006). Trasplante de órganos y bioética Ética clínica Una perspectiva transfuncional. (1.a edición, pp. 375-400). México: Corinter.

Angelcos, N. (2017). Subjetividad, cuerpo y afecto en la teoría sociológica. Estudios Avanzados, (26), 76-94 [consultado 7 Oct 2018]. Disponible: http://www.redalyc.org/articulo.oa?id=435552870005.

Battan, A. (1999). Filosofía del cuerpo o filosofía del alma. Páginas de filosofía; 8(6), 61-66.

Beorlegui, C. (2017). Filosofía de la mente: visión panorámica y situación actual. Realidad: Revista de Ciencias Sociales y Humanidades. [S.l.], n., 111, 121-160 [consultado 14 Sep 2018]. Disponible: https://www.lamjol.info/index.php/REALIDAD/article/view/3420.

Bergel, S. D. (2007). Bioética cuerpo y mercado. Revista Colombiana de Bioética [Internet]., 2(1), 133-164 [consultado 04 Nov 2018]. Disponible: http://www.redalyc.org/articulo.oa?id=189217294007.

Brahams, D. (1998). Editorial: Body parts as property. Medico-Legal Journal; , 66(2), 45-47.

Burgos, J. M. (2017). Repensar la naturaleza humana (1.a - edición). México: Siglo XXI editores.

Crisorio, R. (2016). Sujeto y cuerpo en Educación Didaskomai. Revista de Investigaciones sobre la Enseñanza. $n^{\circ}, \quad 7,3-21$ [consultado 14 Sep 2018]. Disponible en: https://www.colibri. udelar.edu.uy/jspui/handle/123456789/9296.

Delormé de B., C. (2016). $\Psi$ ?XH y $\Sigma \Omega$ MA Una reflexión sobre la relación entre alma y cuerpo. Daimon. Revista Internacional de Filosofía. Suplemento, 543-551.

Escobar:-Triana, M. D. J. (2007). Bioética, cuerpo humano, biotecnología y medicina del deseo. Revista Colombiana de Bioética, 2(1), 33-51 [consultado 14 Ago 2018]. Disponible en: http://www.redalyc.org/articulo.oa?id=189217294003.

Garcìa G.F E. (2005). Diccionario enciclopédico de Bioética (1.a edición, pp. 20). México: Trillas.

Gómez-Alvarez, J. E. (2003). Los Trasplantes. (1.a edición). México: Universidad Anáhuac.

Hudson, M. (1997). J Clin Pathol 1997, 50, 90-91 [consultado el 14 Nov 2019]. Disponible en: https://jcp.bmj.com/content/jclinpath/50/2/90.full.pdf.

Jonson, F. (2011). El cuerpo como posibilidad de la vida: el modo de despliegue del mundo concreto. Alpha, 115-130 [consultado 24 Nov 2018]. Disponible en: www.https://scielo.conicyt. cl/scielo.php?script=sci_arttext\&pid=S0718-2012011000200009.

Kaan, S. H. T. (2017). Asian Who Owns Your Body? Bioethics Review., 9, 415-425.

Kimberly, A. W. y Dina, S. (2009). The body, ashes /exhumation -Who has the last word? Whaley Estate Litigation. [consultado el 10 Oct18]. Disponible en: www. welpartners.com/resources/WEL_BodyAshesExhumation.pdf.

Komesaroff, P. A. y Gardner, S. M. (2015). Human Body. En H. Ten Have (Ed.), Encyclopedia of Global Bioethics. Springer, Cham [consultado 10 oct 2018]. Disponible en: https://link.springer. com/referenceworkentry/10.1007/978-3-319-05544-2_230-1\#howtocite.

Mendoza-Valdés, R. (2013). Ethos del cuerpo humano: responsabilidad y don Una visión heideggeriana. Cuadernos de Ética]., (28), 41 [aproximadamente 24 p.]. [consultado 14 Sep 2018]. Disponible en: http://aaieticas.org/revista/index.php/cde/article/view/50. 
Oliva-Portolés, A. (2015). Hacia una ontología social del cuerpo en Butler: análisis y límites. Investigaciones Feministas, (6), 85-107.

Ramírez, M. T. (2017). El cuerpo por sí mismo De la fenomenología del cuerpo a la ontología del ser corporal. Open Insight., 14(8), 49-68.

SSA. (2018). Ley General de Salud. México. [consultado 7 Oct 2018]. Disponible en: http://www.salud.gob.mx/cnts/pdfs/LEY_GENERAL_DE_SALUD.pdf.

Tealdi, J. C. (2008). (Director) Diccionario latinoamericano de bioética (1. e edición, pp. 94). Bogotá: UnescoUniversidad Nacional de Colombia.

Van Dick, J. (2006). Enseñanza de la ética en la práctica clínica Ética clínica. Una perspectiva transfuncional (1. - edición, pp. 61-89). México: Corinter.

Vásquez Rocca, A. (2008). Las metáforas del cuerpo en la Filosofía de Jean-Luc Nancy: Nueva carne, cuerpo sin órganos y escatología de la enfermedad Nómadas. Critical Journal of Social and Juridical Sciences [Internet]., 18(2) [aproximadamente 11 p.]. [consultado 10 Nov 2018]. Disponible en: https://www.redalyc.org/articulo.oa?id=18101819. 